\title{
Client-based Experiential Learning and the Librarian: Information Literacy for the Real World
}

Andy Spackman

Brigham Young University, andy_spackman@byu.edu

Follow this and additional works at: https://scholarsarchive.byu.edu/facpub

Part of the Information Literacy Commons

\section{Original Publication Citation}

Andy Spackman (2016) Client-based experiential learning and the librarian: Information literacy for the real world, Journal of Business \& Finance Librarianship, 21:3-4, 258-273, DOI: 10.1080/ 08963568.2016.1226616

\section{BYU ScholarsArchive Citation}

Spackman, Andy, "Client-based Experiential Learning and the Librarian: Information Literacy for the Real World" (2016). Faculty Publications. 1771.

https://scholarsarchive.byu.edu/facpub/1771

This Peer-Reviewed Article is brought to you for free and open access by BYU ScholarsArchive. It has been accepted for inclusion in Faculty Publications by an authorized administrator of BYU ScholarsArchive. For more information, please contact ellen_amatangelo@byu.edu. 


\title{
Client-based Experiential Learning and the Librarian: Information Literacy for the Real World
}

\begin{abstract}
Business schools have increasingly turned to client-based experiential learning to better prepare their graduates with skills and abilities that translate to the workplace. The shift from academic learning to experiential learning requires a corresponding shift in the way librarians approach information literacy. This article explores this trend through the literature and through personal interviews and proposes ways in which library instruction, collection development, and liaison relationships can be tailored to meet the needs of experiential learners.
\end{abstract}

\author{
Author \\ Andy Spackman \\ Business and Communications Librarian \\ Brigham Young University \\ 1212 HBLL \\ Provo, UT 84602 \\ andyspackman@byu.edu
}




\section{Introduction: Client-based Experiential Learning}

The importance of learning through experience has been contemplated by philosophers both classical and modern (for examples see Aristotle, Nicomachean Ethics, Book 2; and Dewey, 1938). The term "experiential learning" is sometimes used with precision, as with the Experiential Learning Theory propounded by Kolb in 1984 to describe a model or process that aids in learning from experience (2014). More often, the phrase is used broadly, and many forms of learning by doing have been described as experiential learning. The experiential learning umbrella is large enough that a survey of one university's departments showed that 91 percent include experiential learning in their curriculum in some form; however, only 6 percent defined the experiential learning as a "real world" experience, with another 20 percent referring to internships (Rosenstein, Sweeney, \& Gupta, 2012).

While experiential learning is a broad concept in education philosophy, experiential learning in business education increasingly refers to programmatic learning that addresses a problem situation posed by a real-world client, usually external to the university. For example, an automobile manufacturer could commission a student team to identify opportunities and recommend strategies for entering a new market in sub-Saharan Africa, or a local internet startup could commission a student team to develop psychographics for target demographics and recommend appropriate positioning. Experiential learning projects can also serve nonprofit and social organizations, broadening business education through community engagement and an 
element of ethical responsibility (Cook, Campbell, \& Kopp, 2013; Godfrey, Illes, \& Berry, 2005).

Such client-based experiential learning differs from the traditional internship in at least four ways: the programs are integrated within the curriculum, the projects are team-based, they are commissioned to address a client's specific need, and students are accountable both to the client and to the faculty advisor or university (Llano, Allen, Grant, Dambacher, Heale, \& Kasapi, 2014). Experiential learning programs can vary in their particulars and in their names. They are often structured as consulting firms; they may take the form of capstone experiences. In addition to experiential learning, other labels include action learning, service learning, field studies, oncampus internships, live-case studies, student team consultancies, and university business advising.

For the purposes of this article, experiential learning will refer to these types of clientbased programs.

\section{Experiential Learning in Business Education}

Institutions of higher learning are the product of the tension and synergy between scholarship and education, research and teaching. This duality is especially pronounced in business schools, leading Bailey and Ford to argue that business “differs from some other academic disciplines in that the domain of scholarship-with its emphasis on explanation and knowledge generation — and the domain of education — with its emphasis on practice and action—require different approaches” (1996, p. 8). Or, as Hodge, Proudford, and Holt phrase it: "Leadership, among other business topics, requires space to think and act. Relevant learning must be taught in motion and not just in theory” (2014, p. 8). 
Increasingly, employers expect plug and play recruits—students who graduate with skills and abilities that can immediately benefit their organization with minimal on-the-job training. At the same time, for many students, the acquisition or creation of knowledge is not the ultimate objective of higher education. They shop for universities based on job placement rates and insist on courses that translate directly to careers.

The need to move beyond the text and the lecture and toward learning models that emphasize real-world capabilities is not entirely new. The case method of teaching, now widespread in business education, was begun at Harvard Business School in an effort to accomplish this redirection toward the real world. "The assumption was the case model would trigger deeper learning, and help to move students from untethered theory to anchored learning” (Hodge et al., 2014, p. 9).

But the case method, long dominant, has come under question. "Although cases help traditional-age undergraduate students with the assessment of many situations, cases alone are insufficient in bridging the gap between these students' knowledge, experience, and their preparation for the real world" (Joshi, Davis, Kathuria, \& Weidner, 2005, p. 676). Because "the most important influence on self-efficacy is personal experience,” McCarthy and McCarthy argue for mandatory real-world experiences for business students, "direct, personal encounter[s]" that the case method cannot provide (2006, p. 201-202). Internships are one common solution to providing such encounters and real world experiences, but it is "challenging to create consistent academic value through internships” because they are unstructured learning experiences with limited integration in the curriculum, and they do not close the learning cycle through reflection and conceptualization (Kosnik, Tingle, \& Blanton, 2013, p. 617). 
Experiential learning is increasingly acknowledged as key to bridging the gap between theory and practice. In its accreditation standards, the Association to Advance Collegiate Schools of Business now specifies an expectation for business schools to provide "a portfolio of experiential learning opportunities for business students, through either formal coursework or extracurricular activities, which allow them to engage with faculty and active business leaders” (2013, p. 37). Unfortunately, there are no reliable statistics on the growth of client-based experiential learning in business education, although a 2009 survey showed 65 percent of responding U.S. business schools practiced it in some form (Sciglimpaglia \& Toole). Moreover, until recently, implementation of experiential learning was primarily "ad hoc and with limited context ... dictated by access to a specific instructor or institution” (Hodge et al., 2014, p. 4). This irregularity has, for many institutions, gradually solidified into programmatic structures, often administered through a career services office, or as an office or center of experiential learning (see Sidebar for perspectives from two directors of such departments).

David Comisford, Founder and CEO of EduSourced, describes this process as "formalizing" and links it with the adoption of experiential learning as a strategic emphasis by college and university administrators (personal communication, April 14, 2016). EduSourced, launched in Fall 2014, provides a software platform that centralizes and facilitates experiential learning project management for the university, the client, and the student practitioners (www.edusourced.com). The initial success of this service is, by itself, evidence that client-based experiential learning is becoming more structured at many universities. Comisford, who has himself commissioned experiential learning teams from Ohio State University’s computer science program, says the benefits to students from participating in these programs can be seen in 
the way successful projects strengthen client organizations’ recruiting relationships with the university, with clients sometimes hiring students directly from the project.

This stands in contrast to findings from the most recent survey of employers conducted for the Association of American Colleges and Universities, which revealed that 80 percent of employers want recruits with real-world skills, but only 23 percent say college graduates are prepared to apply their skills to real-world situations (Hart Research Associates, 2015). In this sense, experiential learning is the best demonstration of a student's abilities. It can provide competitive advantage for students by better preparing them for employment, for employers by providing them with better prepared recruits, and for universities by attracting recruiters that seek better-prepared students.

\section{Experiential Learning and Student Information Needs}

As the role of client-based experiential learning grows, student information needs evolve. Unlike doctoral students planning their dissertations, experiential learners might give a poor relevancy ranking to a librarian who teaches them how to conduct a proper literature review. More relevant than being able to identify a peer-reviewed article is the ability to evaluate an analyst's expertise, and more needed than familiarity with aggregators of scholarly journals is familiarity with company databases and providers of secondary industry and market research. These are the types of information and tools that students will use in their careers after graduation, and gaining experience with them translates directly to their marketability as employees.

Experiential learning not only requires different kinds of information, but a different understanding of the nature of information. Bailey and Ford assert that the traditional scholarly 
or "scientific paradigm assumes that information is objective and that its meaning is clear and definitive.... This orientation implies that the primary goal of decision makers is to collect and analyze data in order to dispel and, if possible, altogether eliminate uncertainty so that choice is between perfectly known alternatives” (1996, p. 9). But after graduation students will embark on careers in "inherently ambiguous business environments" where alternative choices and their outcomes cannot be perfectly known. In the real world, information literacy necessarily includes more than access or application; it encompasses evaluation and interpretation. "This involves drawing a distinction between uncertainty as an absence of information, ambiguity as the existence of multiple conflicting interpretations, and politics as the presence of alternative agendas” (Bailey \& Ford, 1996, p. 9).

The ambiguity inherent in real-world projects makes information literacy more imperative, and provides opportunities for librarians to address deeper principles that sometimes don't find their way into typical one-shot library instruction sessions. Despite their tendency to be idiosyncratic, the information needs of experiential learning can still be addressed by library instruction that is aligned with recognized principles and standards of information literacy, just as well as case-based and other forms of active learning can be (Fiegen, Cherry, \& Watson, 2002; Phillips, 2011; Riddle, 2003; Spackman \& Camacho, 2009).

For example, the Association of College and Research Libraries’ Framework for Information Literacy for Higher Education posits that “information has value” (2016). The nuances of this principle as discussed in the Framework are well-illustrated in an experiential learning context where students must grapple with a real-world problem for which good information is not easily obtained. As Andrew Allen, Director of Illinois Business Consulting, puts it, “Google will give you answers to big questions, and if you're lucky you'll find some 
things that are really specific, but clients aren't satisfied with a Wikipedia answer.” This “forces [students] to figure out the relevance of different sources and what weight to give them" (personal communication, April 18, 2016). The very fact that clients, in many cases, pay significant fees to the university in order to commission student teams communicates the idea that information has value. Because experiential learning programs typically include hybrid academic/commercial projects, students must straddle a complex space in relation to the ethical, contractual, and legal use of information, and here again they gain understanding of the value of information.

Another element of the Framework is that "authority is constructed and contextual." In navigating a real-world problem for which peer-reviewed, scholarly publications may not have much relevance, students must necessarily contemplate different types and degrees of authority. Sources of information may include company annual reports, journalism in an industry newsletter, data from a government website, the previously published analyses of various research firms, and survey data or other primary research the student team generates itself. Experiential learners must not only assess the methodology and authority of varied information sources, but ultimately they are also constructing their own authority as they complete their research and deliver their conclusions and recommendations to the client.

The nuances in the other aspects of the Framework ("information creation as a process," “research as inquiry," "scholarship as conversation," and "searching as strategic exploration”) can be similarly highlighted by the needs of a real-world project. Client-based experiential learning places students in the same uncertain and ambiguous information ecologies in which they will spend their careers. Information literacy has always been necessary to thrive in such 
environments, and however convincing a professor or librarian may be in proclaiming this, there is no better witness than the students' personal experience.

It should be noted that when information literacy is taught or discussed, librarians may be able to focus more on actual principles if we show greater flexibility in the language we use. "Information literacy" is a term of art. Even though there is clear evidence that abilities inherent to information literacy are valued, it and related library jargon hold little familiarity or obvious meaning in the business world or even among most academics outside of the library (Conley \& Gil, 2011; Klusek \& Bornstein, 2006; O’Connor, 2008; Sokoloff, 2012; also note the absence of any mention of "information literacy" in the interview sidebar). There may be no quick solution to the problem of terminology, but communicating the concepts and importance of information literacy can be easier in the inductive context of experiential learners' real-world projects.

One other consideration adds a new dimension to the experiential learner's need for information literacy. Because experiential learning projects involve multiple stakeholders, more relies on the students' performance than just a grade for a course. Mark Callister, of Brigham Young University's School of Communications, makes this point: “Clients are literally spending thousands and even millions of dollars on marketing and advertising strategies based on research that we provide. Students' ability to find resources, uncover insights, and to convert those into strategy from information is vital” (personal communication, April 15, 2016). When students work on real-world projects, their success not only impacts their own careers, but also the reputation of the university (Llano et al., 2014). Librarians can facilitate this success by adapting their instruction, collection development, and liaison practices to be more relevant in the experiential learning context. 


\section{Experiential Learning and Library Instruction}

"There is no doubt that the scientific approach is appropriate for the study of management. But it is less viable as an approach to teaching business studies. The practice of management is best taught as a craft; rich in lessons derived from experience and oriented toward taking and responding to action."

- Bailey \& Ford, 1996, p. 9

Just as the shift from academic learning to experiential learning requires a shift in professors' pedagogy, so too librarians must reframe our approach to library instruction and information literacy. For instance, navigating scholarly journals and properly employing citation styles may become less important than understanding why different market research firms give contradictory figures for an industry's size. Similarly, the fact that deceptively simple questions like "what is the market size for widgets?” may require labyrinthine research—and may not even have an answer — can provide opportunities to introduce deeper principles of information literacy (Hesseldenz, 2012; Phillips, 2010).

The ambiguity of real-world projects means that librarians must help students form realistic expectations for their research outcomes. Secondary research that is directly relevant to their problem may not be available, or may not even exist. This provides an opportunity for instruction on the differences between primary and secondary research, including the relative costs in money and time involved. Librarians can further illustrate the principle that information has value by pointing out the regular prices of research reports and leading students through a discussion about what the library actually pays, why vendors might be willing to provide the 
library discounts, and what risks vendors can expose themselves to by doing this. Such a discussion leads naturally to instruction on licensing terms and the types of use that are and are not appropriate.

Not only do students need the ability to value and evaluate information, but to apply it in ways that might not be obvious. This can include the use of proxy data, such as using the findings of a market research report to justify a recommendation in a totally different market which is analogous in some aspect. For instance, students researching the market for designer socks might apply consumer insights from a report on celebrity-branded headphones if they determine the categories share a target demographic.

The relevance of such skills translates directly to students' careers, where they will inhabit similarly "messy" information environments (Phillips, 2010). Experiential learners are motivated because they are working for real clients on actual projects which are similar to the work they expect to do after graduation. Because of this, they are especially receptive to library instruction if it is framed within the context of their specific projects. For this reason, library instruction may not be most efficient in large classroom settings. Instead, meeting with individual teams, or with teams grouped according to the similarity of their projects, is more effective, particularly if the librarian is provided with project descriptions beforehand.

At the University of Illinois at Urbana-Champaign, business librarians Becky Smith, Carissa Phillips, and Yoo-Seong Song take a two-pronged approach to supporting students in experiential learning programs (personal communications, April 18-19, 2016). First, the Illinois Business Consulting (IBC) program provides the library with project descriptions so that IBC student teams can meet with librarians to receive customized instruction and research consultations. Second, students taking an Information Consulting course at the Graduate School 
of Library and Information Science are embedded within some IBC teams, providing research services and acting as liaisons between the team and the library.

Managing expectations is a key part of library instruction and information literacy not only for the students, but also for their clients. These companies and organizations may have been attracted to commission an experiential learning project partly because of the information resources that are at the students' disposal. However, they usually have little understanding of exactly what those resources may or may not be able to provide, and an even less clear idea of what copyright, licensing, or ethical considerations may come into play as students use these tools in support of their project. These clients may need to navigate the information literacy learning curve just as the students do, yet librarians typically do not have access to clients. Instead, client expectations must be managed by the students themselves, or by their faculty advisors or the administrators of the university's experiential learning program. This need for client education is actually another opportunity for students to exercise their information literacy. Of course, even greater importance must be placed on library instruction if students are to effectively negotiate expectations with clients, and it becomes essential that program administrators and faculty advisors themselves have a clear understanding of these issues.

\section{Experiential Learning and Collection Development}

Student use of library resources in the service of external clients introduces ethical, contractual, and legal complexities not only for library instruction, but also for collection development. Indeed, librarians and business information vendors both may find themselves reevaluating or even renegotiating their licenses to accommodate these evolving needs. Even if they don't specifically address experiential learning, many database licenses include language 
stipulating that access is provided for academic, noncommercial use. For the business school, its students, and the librarians who serve them, this language may already seem murky, if not contradictory. The added nuances of client-based experiential learning, in all of its various forms, further confuses the academic/noncommercial distinction.

Good practices and reasonable boundaries can be stretched in a variety of ways. For instance, some vendors may not become exercised about entrepreneurship students accessing databases to research market conditions for their fledgling start-up. But even the most liberal vendor will justifiably show concern at the possibility of lost revenue if companies were to commission student teams simply to take advantage of their library access. Nevertheless, the opportunity to initiate a relationship with students and thereby gain brand loyalty with future professionals holds a strong attraction for many vendors. And in an example of classic price discrimination, vendors and universities both benefit through academic discounts, universities because they gain access to resources they might not otherwise afford, and vendors because they gain additional revenue, even if it’s at a lower price point, for content they have already created for their corporate customer base.

Some librarians, caught between pressing user needs and vague licensing agreements, rely on common sense guidelines, such as the concept that if a student's curriculum consists of experiential learning, and their use of library resources is in direct support of that curriculum, then it qualifies as an academic use. This should be colored with the additional caveat that while students may reference, quote, and cite licensed content, they cannot simply provide that content to external clients or allow clients to use student passwords, etc., to gain direct access. Ultimately such an approach, where database access is only an input and the deliverable for the client is the students' own analysis, is not only ethical, but best fulfills the interests of the students, the client, 
and the university. In any case, each librarian and institution is responsible for negotiating and adhering to its own licenses with vendors, and best practice is to communicate with specific vendors when in doubt. By taking and communicating systematic steps to safeguard intellectual property and educate users about licensing restrictions, librarians can ensure healthy vendorlibrary partnerships.

In addition to steering constituents through licensing issues, librarians serving experiential learning programs must be nimble in their selection of resources, continuously adapting library collections to the fluid and disparate projects undertaken by students. This suggests at least a partial move away from the traditional approach of subscribing to bundles of content from key secondary research providers, toward a model where less constrained budgets can be tapped for the purchase of specific pieces of content or single reports from any provider. This is a just-in-time model, rather than just-in-case, and can more precisely and quickly meet the needs of experiential learners. It also raises its own set of licensing issues, and the questions of where the library should store content acquired in this way, how it should provide authenticated access, and whether the experiential learning programs should contribute funding. The increased flexibility of such models also implies that librarians must move quickly in evaluating and selecting resources—resources that may be totally unfamiliar to them, provided by vendors that may be unfamiliar with the library world. This requires librarians to work closely with experiential learners, and their advising faculty and program administrators, to identify and evaluate resources.

The fact that many of the tools and databases most relevant to experiential learners are not native to libraries or academia complicates collection management and development in several other ways. These resources may not provide extensive documentation, or export citation 
data to bibliographic utilities. More importantly, their access models might be less open than the library ideal, restricting use to certain locations, certain users, or certain times of year. And if libraries are a small fraction of their business, they may not provide high levels of support or customization. However, the opportunity to gain experience with these real-world tools makes the library relevant to a segment of students it might not otherwise reach. Such resources enrich experiential learning, and students’ resumes are strengthened when they can cite proficiency with the real-world tools and techniques they would otherwise have to learn on the job. As Brigham Young University’s Mark Callister explains: “Every semester I bring my research methods students to the university library to receive training in how to use marketing databases. Such training has been key in providing important insights for our clients and for giving our students an advantage in their internship and job searches” (Personal Communication, April 15, 2016).

\section{Experiential Learning and Liaison Relationships}

While there are no reliable, broad-based statistics on the growth of client-based experiential learning in business education, many librarians (myself included) can attest at least anecdotally to one evidence: the proportion of research consultations librarians conduct with teams rather than individuals has risen and continues to rise. Reference or research consultations with experiential learning teams often extend longer and require more preparation from the librarian. The length and scope of projects often results in multiple follow-up consultations, with the librarian sometimes becoming a kind of consultant for the team throughout the semester (Griffis, 2014). Innovative models, like the embedding of library science students in experiential teams at the University of Illinois at Urbana-Champaign could help meet this need. Libraries 
tracking reference statistics must also decide whether to count team consultations as single interactions, or whether to count each team member separately.

As experiential learning programs have become more established, they have also expanded beyond the business school. Other disciplines are forming their own programs, and cross-disciplinary programs are becoming more common. Increasingly, business librarians are serving experiential learning teams comprised not only of business students, but students from engineering, design, communications, technology, science, and social science, all bringing their different abilities and perspectives to bear on the projects commissioned by real-world clients. David Comisford of EduSourced points out that the interdisciplinary nature of such teams mimics real-world teams (personal communication, April 14, 2016). It also raises new challenges for business librarians, who must develop approaches to impart business information literacy to non-business students.

Clearly, robust liaison relationships are essential if the library is to serve the dynamic needs of experiential learners. Constant collaboration positions librarians to understand both the overarching trends in experiential learning at their institutions, and the specific needs of current projects. As described by Patrick Griffis, such collaboration can evolve into a partnership where the librarian works together with faculty in designing experiential courses and the library workshops and research consultations to support them (2014).

As collaboration deepens, program administrators and faculty advisors become allies in promoting librarians and library resources and in communicating licensing issues both to students and clients. Librarians must consider who their key contacts will be in relation to experiential learning, whether it be the individual faculty member leveraging personal industry connections to generate a real-world capstone project for her course, or the director of a formally 
organized experiential learning office. In cases where experiential learning is more structured, librarians can benefit from clearer lines of communication and centralized points through which they can access students. But even at universities that have achieved success by hiring former consultants, recruiters, or practitioners to administer their experiential learning programs, faculty buy-in is still essential for program success, and for the library liaison relationship.

\section{Conclusion: Experiential Learning and the Librarian}

"My prediction is that [experiential learning] will become more integrated into everything or almost everything a student does, as opposed to being an elective."

- Andrew Allen

Business schools are increasingly orienting curricula around experiential learning, assigning students real-world projects that address the needs of actual clients. This transition from academic to experiential learning only increases the need for information literacy, and if librarians appropriately adapt their instruction, collection development, and liaison efforts, the relevance of information literacy concepts and skills will become more evident to students. By positioning themselves as essential facilitators of experiential learning, librarians better benefit students, faculty, and even the external clients.

Students place high importance on applied learning experiences, and view experiential learning as more effective than readings, lectures, or cases (Hart Research Associates, 2015; Mottner, 2010). They can more easily see the relevance of their education when it includes opportunities for them to actually practice what they plan to do in their future careers. By 
providing this, experiential learning also makes their education relevant in the eyes of employers. The same applies for information literacy and library instruction: students see the relevance to their personal interests and goals when it helps them to succeed in real-world projects.

Faculty likewise form stronger bonds with the library when librarians adapt to the experiential learning faculty are building their courses around, and if librarians assist students to succeed in their projects, the clients that benefit will grow closer in their relationships with the university. This can translate not only to additional projects but to increased recruiting and sponsorships. These are outcomes that powerfully demonstrate the library's value.

As in the real world, students will rarely find easy or unambiguous answers to the questions and problems they face in experiential learning projects. By adapting to their needs, librarians can help these students gain experience finding, evaluating, and applying actionable business intelligence to form their own conclusions, make decisions, and convincingly defend their recommendations. In this way, librarians help students achieve a competitive advantage both in their education and in the workplace. 


\section{References}

Association of College and Research Libraries (2016). Framework for Information Literacy for Higher Education. Chicago, IL: ACRL. Retrieved from http://www.ala.org/acrl/standards/ilframework

Association to Advance Collegiate Schools of Business (2013). Eligibility Procedures and Accreditation Standards for Business Accreditation. Tampa, FL: AACSB. Retrieved from http://www.aacsb.edu/accreditation/standards/2013-business

Bailey, J., \& Ford, C. (1996). Management as science versus management as practice in postgraduate business education. Business Strategy Review, 7(4), 7-12.

Conley, T. M., \& Gil, E. L. (2011). Information literacy for undergraduate business students: Examining value, relevancy, and implications for the new century. Journal of Business \& Finance Librarianship, 16(3), 213-228.

Cook, R. G., Campbell, D. K., \& Kopp, A. (2013). Student focused community engagement: The SBI program as a bridge into the community. Small Business Institute Journal, 9(2), 110.

Dewey, J. (1938). Experience and education. New York, NY: Macmillan.

Fiegen, A. M., Cherry, B., \& Watson, K. (2002). Reflections on collaboration: Learning outcomes and information literacy assessment in the business curriculum. Reference Services Review, 30(4), 307-318.

Godfrey, P. C., Illes, L. M., \& Berry, G. R. (2005). Creating breadth in business education through service-learning. Academy of Management Learning \& Education, 4(3), 309323. 
Griffis, P. J. (2014). Information literacy in business education experiential learning programs. Journal of Business \& Finance Librarianship, 19(4), 333-341.

Hart Research Associates. (2015). Falling Short? College Learning and Career Success. Association of American Colleges and Universities. Retrieved from https://www.aacu.org/leap/public-opinion-research

Hesseldenz, P. (2012). Information literacy and the evolving MBA degree. Journal of Business \& Finance Librarianship, 17(4), 287-299.

Hodge, L., Proudford, K. L., \& Holt, H., Jr. (2014). From periphery to core: The increasing relevance of experiential learning in undergraduate business education. Research in Higher Education Journal, 26, 1-17.

Joshi, M. P., Davis, E. B., Kathuria, R., \& Weidner, C. K., II. (2005). Experiential learning process: Exploring teaching and learning of strategic management framework through the winter survival exercise. Journal of Management Education, 29(5), 672-695.

Klusek, L., \& Bornstein, J. (2008). Information literacy skills for business careers. Journal of Business \& Finance Librarianship, 11(4), 3-21.

Kolb, D. (2014). Experiential learning: Experience as the source of learning and development (2nd ed.). Upper Saddle River, NJ: Pearson FT Press.

Kosnik, R. D., Tingle, J. K., \& Blanton, E. L. (2013). Transformational learning in business education: The pivotal role of experiential learning projects. American Journal of Business Education, 6(6), 613-630.

Llano, T., Allen, A., Grant, T., Dambacher, J., Heale, JP., \& Kasapi, M. (2014). University Business Advising. Washington, DC: University Industry Demonstration Partnership. 
McCarthy, P., \& McCarthy, H. (2006). When case studies are not enough: Integrating experiential learning into business curricula. Journal of Education for Business, 81(4), 201-204.

Mottner, S. (2010). Service-learning in a nonprofit marketing course: A comparative case of pedagogical tools. Journal of Nonprofit \& Public Sector Marketing, 22(3), 231-245.

O’Connor, L. G. (2008). The diffusion of information literacy in academic business literature. Journal of Business \& Finance Librarianship, 13(2), 105-125.

Phillips, C. M. H. (2010). Students' research experiences during consulting projects: Three themes emerging from case studies. Behavioral \& Social Sciences Librarian, 29(2), 91108.

Phillips, C. M. H. (2011). Student consultants’ perceptions and valuations of research skills. Reference Services Review, 39(3), 514-530.

Riddle, J. S. (2003). Where's the library in service learning?: Models for engaged library instruction. The Journal of Academic Librarianship, 29(2), 71-81.

Rosenstein, A., Sweeney, C., \& Gupta, R. (2012). Cross-disciplinary faculty perspectives on experiential learning. Contemporary Issues in Education Research, 5(3), 139-144.

Sciglimpaglia, D., \& Toole, H. R. (2009). Use of student field-based consulting in business education: A comparison of American and Australian business schools. Journal of Education for Business, 85(2), 68-77.

Sokoloff, J. (2012). Information literacy in the workplace: Employer expectations. Journal of Business \& Finance Librarianship, 17(1), 1-17.

Spackman, A., \& Camacho, L. (2009). Rendering information literacy relevant: A case-based pedagogy. The Journal of Academic Librarianship, 35(6), 548-554. 


\section{Sidebar: Perspectives from Experiential Learning Program Directors}

Roger McCarty has been Director of Experiential Learning at Brigham Young University’s Marriott School of Management since 2007. He previously worked for The Dow Chemical Company, spanning 30 years in a variety of positions ranging from Chemical Engineer to Director of New Business Development to Director of Staffing and Learning.

Matthew Lynall is Clinical Associate Professor at Purdue University’s Krannert School of Management, where he directs the Experiential Learning Initiative which he founded in 2009. He received a $\mathrm{PhD}$ in Organizational Behavior at the University of Western Ontario. Previously he was a partner in a management consulting firm and worked in telecommunications and automotive metal fabrication.

What do you see as the role of experiential learning in business education today, and how have you seen that role evolve over time?

McCarty: There has been a progression from just teaching principles, to tools, to cases, and then to actual project work over the last 40 years since I got my engineering degree and MBA. Since I came to BYU we have significantly increased the number of graduate management students participating in experiential work/consulting programs from 20 to 50 students per year (when I came) to more than 150 students participating in experiential work programs per year. In 2008 when we started experimenting with undergraduate 
experiential work programs there were no students involved in programs. In 2016 we will have more than 1,400 students involved in On Campus Internships alone.

Lynall: Since we launched the Experiential Learning Initiative (ELI) in 2009, approximately 75\% of each subsequent MBA cohort has participated in one of the experiential learning programs. The main program is Corporate Consulting, in which students provide consulting services to major corporations affiliated with Purdue as recruiters of research partners. We also have a Technology Commercialization program for students to work with faculty and graduate researchers to develop commercialization plans for their research. Over 800 students have undertaken more than 160 projects. Since its initiation, ELI has evolved from an MBA-only to an interdisciplinary program, which is open to graduate students across Purdue—students from 7 colleges and 15 academic units (i.e. schools, departments) have joined the MBA students on the various projects. This interdisciplinary approach is a core element and, we believe, an essential component of business education. By providing the opportunity for management students to work closely with their counterparts in science, technology, and engineering they all experience the challenge and benefit of applying multiple perspectives to the project.

\section{How does experiential learning change the research and information needs of students?}

Lynall: Unlike traditional academic instruction where the required information is provided (e.g. cases, industry notes), students are required to determine by themselves their information requirements and identify appropriate information resources. Usually there is a short and steep learning curve as the students use secondary research to familiarize themselves with 
the project sponsor and their market and industry environment before directly engaging with the company to finalize the scope of the project.

McCarty: The Students need much more practical information to meet the needs of real business. It becomes less about the numbers, and more about the interpretation of information. Students go from collecting data, to managing data, to comparing data, to integrating data findings, to synergizing data elements, to challenging the individual data sources and findings based on the insights gained through the research. Students are much more focused on gaining insight, understanding, and clarity towards specific recommendations of their own making; not just trying to figure out what the professor thinks the answer should be.

\section{What role does the effective use of information play in student decision making and success?}

McCarty: Decision making based on insight gained from information, like every other skill or talent, is developed through instruction and practice. The professor can teach, demonstrate, and critique, but the student cannot play a trombone until he picks it up and tries it out. The student needs a variety of information types available to help them move from rudimentary information retrieval and analysis to sophisticated information creation through multiple information sources. So having information sources that are prepackaged is valuable for the early learner, while more technically based information requiring significant analysis and sophisticated tools must be available for the more advanced experiential learner. Also, as we reach into the business world for our problem 
sources, we need a wide variety of information sources to meet the diverse needs of our clients.

Lynall: The projects require the students to get quickly up to speed on the company, its market, competition, and other factors that affect its strategy and performance. This contextual understanding is essential for the students to successfully structure and execute their projects. Opinions and beliefs are not the basis for the project sponsors’ decisions and actions that the students will be informing. Our students understand that their findings and recommendations must be based on facts and analysis. We use a hypothesis-driven approach to ensure purposeful collection and analysis of data.

\section{How can librarians best support experiential learning programs?}

Lynall: Following the proverb: "You give a poor man a fish and you feed him for a day. You teach him to fish and you give him an occupation that will feed him for a lifetime,” the role of the librarians is to show the students how to find the information, rather than do the research for them. As a major university, we have access to valuable (and expensive) databases and information resources. Before the semester, we provide the librarians with descriptions of the projects that the students will be undertaking so that they can be prepared for the students and have already identified databases and other resources that are pertinent to the projects. One of our librarians also participates in a class for each semester's cohort to provide them with an overview of the library system and the resources that are typically used to support the experiential learning projects. 
McCarty: Having a diverse and progressively more sophisticated set of information sources is critical. Librarians should work with the experiential leaders and professors to determine the types of data sources most useful. Then as the students work with business clients they will learn of more information sources that will be valuable in the business world. The librarian needs to be flexible and adapt to these evolving needs over time. The students may become the best source for new and cutting edge information sources as they work in experiential learning situations. The librarians need to be constantly learning and adapting to the information needs of the experiential learners.

\section{Can you share any stories that illustrate students benefiting from librarian support?}

McCarty: There have been many times when students came to me and said they were not able to complete their projects because they could not find information about the market, industry, or competitors. I showed them how to start using the databases and immediately found relevant data. Then I sent them to the librarians and the librarians were able to help them even more focus their searches on rich sources of data and information. The librarians have been so helpful that I have a Business Library link on my Experiential Learning website for all of the student teams. Leticia Camacho [a librarian] has identified specific databases for specific types of data. We also have the contact information so they can set up meetings with her. I show this library link to every class, and many teams use the resource. One student kept track of the reports he used that had a fee associated with the report if he were not a student. He calculated that the reports he used for his project would have cost the company more than $\$ 20,000$ and that does not count the subscription-based databases where no cost was assigned to the [specific] reports he used 
(let me also reiterate that we explain exactly how information retrieved from the databases can be used in reports for the company sponsor without infringing on [licensing agreements]). We have also widely advertised the training and orientation classes offered by Andy Spackman [another librarian] and many students have attended and valued the information and access. I have also posted past training handouts on my website to give more resources to the students before the classes are offered that semester.

We also found that we had a reoccurring need for information about the chemicals and plastics industries due to the companies that were giving us projects. The library worked with us to obtain access to [a specific database] as a resource for our students and greatly increased the relevant data available to our experiential learning students for their projects. The proactive efforts by the librarian were greatly appreciated by the experiential leadership and the students.

Recently I have discovered the geospatial resources at the library and we are using them also. We are doing a project for Papa Murphy’s Pizza where we have identified the demographic characteristics of the most profitable [store locations] and used regressions to find the key correlated demographics. Then we used the geospatial resources to identify the most profitable location tracts for new stores in every state and city. Then we identified the best intersection in the cities and tracks to place the stores. While Papa Murphy's owned the software and data for this geospatial process, they had never used the software in this manner as far as we are aware. So the students not only learned a tremendous amount, they were able to open new concepts for the company sponsor. The 
students never would have been able to utilize these valuable resources without the guidance of the librarian that helped them.

Lynall: We expect the students to arrive at their first meeting with the project sponsor with an understanding of their business, so that they can focus on discussing the scope of the project and how it fits within the company's strategic priorities. One team was so well prepared that they delivered a presentation to the executive sponsor and management team of an industrial electronics company summarizing their initial library research which so impressed the client that it was incorporated into the company's employee orientation and onboarding program.

On another project, involving the adoption of 3D printing for a manufacturer's slow moving spare and replacement parts, through library research the team (with little prior experience in this area) was able to provide a comprehensive briefing on the current and projected capability of 3D printing technology and a highly refined set of criteria for the selection of appropriate parts.

On a project for a cancer research center, a team that had no prior experience or expertise in the life sciences amazed their project sponsor with their understanding and insights into the drug discovery process. In developing a financial model for out-licensing of drug compounds, they were able to obtain data on over 200 licensing deals related to colorectal cancer that resulted in recommendations that caused the organization to radically change its approach to licensing. 


\section{What are your predictions for the future of experiential learning and student information needs?}

Lynall: I believe that experiential learning will be an increasingly important part of the business school curriculum. Ours is a graduate program and we need to provide a similar experience to our undergraduate students. Since the university library system supports multiple constituencies with different needs to access, process, and store information, there will be a need to develop a portal and repository tailored to the needs of experiential learning programs.

McCarty: I think the need for information will only continue to grow in experiential learning as we move into the future. But I believe the largest needs will be: 1 . The identification of relevant and recent data sources; 2 . The tools and processes to analyze the data that is found; 3. The acquisition of insight and understanding, not just data; 4 . The ability to quantify the credibility of sources in an ever-burgeoning information marketplace; 5 . The ability to identify when data is relevant and appropriate to meet their needs, and when insights and data found in the resources of the library are not appropriate for use in the student's project. This evolution to more sophisticated use of data sources will greatly increase the value created by the students in their experiential learning projects and their ability to use data in their future careers. 